\title{
THE INFLUENCE OF Q\&P PARAMETERS ON CARBIDE PRECIPITATION AND MECHANICAL PROPERTIES OF HIGH-CR MARTENSITIC STEEL
}

\author{
Magdalena BAGROWSKA, Adam GOŁASZEWSKI, Wiesław ŚWIĄTNICKI \\ Faculty of Materials Science and Engineering, Warsaw University of Technology, \\ Warsaw, Poland, EU, magdalena.bagrowska@nanostal.eu
}

https://doi.org/10.37904/metal.2019.719

\begin{abstract}
Quenching and Partitioning method of steel heat treatment (Q\&P) [1-4] consists of two steps: partial martensitic quenching $(Q)$ followed by short annealing i.e. partitioning step $(P)$. During partitioning carbon atoms diffuse from supersaturated martensite laths or plates into surrounding untransformed austenite. This process leads to the stabilisation of retained austenite in steel after martensitic transformation. As a result, a two-phase microstructure is obtained. It consists of tempered martensite and stable retained austenite. The presence of stabilised austenite in steel improves the ductility of steel due to the TRIP effect (Transformation Induced Plasticity). The aim of this study was to design the parameters of Quenching and Partitioning (Q\&P) process of $\mathrm{X} 46 \mathrm{Cr} 13$ steel and to investigate the influence of the process parameters on the microstructure and on mechanical properties of this steel. The parameters of Q\&P treatment were determined with the use of dilatometric measurements. To determine phase composition after Q\&P process, magnetic measurements were conducted. The microstructure of martensite and austenite as well as the presence of carbides were examined through Transmission Electron Microscopy (TEM). Changes in hardness after various variants of Q\&P treatment were also analysed.
\end{abstract}

Keywords: Martensitic stainless steel, carbide precipitations, Q\&P processing, retained austenite.

\section{INTRODUCTION}

The Q\&P heat treatment is a relatively new process leading to a two-phase microstructure which contains tempered martensite and thermally stabilised retained austenite [1,5]. The latter was obtained through the increased carbon content. This process can be applied to the corrosion resistant types of steel: ferritic (X6Cr13), ferritic-martensitic (X20Cr13) and martensitic (X30Cr13) [2,3,5]. It was stated that after the Q\&P treatment steel displayed significantly improved mechanical properties with comparison to the same types of steel subjected to conventional quenching and tempering (Q\&T heat treatment). It was shown, that the TRIP effect occurred in retained austenite that was present in steel. This, in turn, resulted in the improved strengthductility balance [2, 3]. With regard to the corrosion resistant types of steel, the research carried out so far on the Q\&P process, worked only on steel with carbon content up to $0.3 \%(\mathrm{X} 30 \mathrm{Cr} 13)$ [3]. The aim of the present study was to investigate the influence of the Q\&P treatment on the mechanical properties of X46Cr13 steel. This aspect has not been investigated yet.

The first step of the Q\&P treatment consists in quenching of steel from the austenitizing temperature to the quenching temperature (QT) which lies between $M_{s}$ and $M_{f}$ (where $M_{s}$ is a martensitic start temperature and $\mathrm{M}_{\mathrm{f}}$ is a martensitic finish temperature). At the $\mathrm{QT}$, steel contains two phases: martensite and unstable austenite. Then, steel is heated to a partitioning temperature (PT) which is higher than QT (it generally lies between 200 $-450^{\circ} \mathrm{C}$ ) and afterwards, it is isothermally annealed at this temperature for the time necessary for redistribution of carbon atoms from supersaturated martensite to the surrounding retained austenite. Austenite enriched with carbon is thereby stabilized. The partitioning process is carried out in order to obtain the sufficient austenite stability by lowering the $\mathrm{M}_{\mathrm{s}}$ below room temperature RT. Finally, steel is cooled down to the room temperature (RT). The Q\&P treatment diagram is presented in Figure 1. 
The Q\&P treatment allows the contents of tempered martensite and of retained austenite in steel to be controlled. Moreover, after the treatment, retained austenite is more susceptible to the TRIP effect. The volume fraction of martensitic transformation increases due to lowering of QT and consequently, the content of austenite in steel decreases. During partitioning, the $\mathrm{M}_{\mathrm{s}}$-temperature of retained austenite is lowered and the stability of austenite increases. The insufficient amount of austenite may lead to its excessive stability during the partitioning process. This, in turn, may prevent the TRIP effect [5].

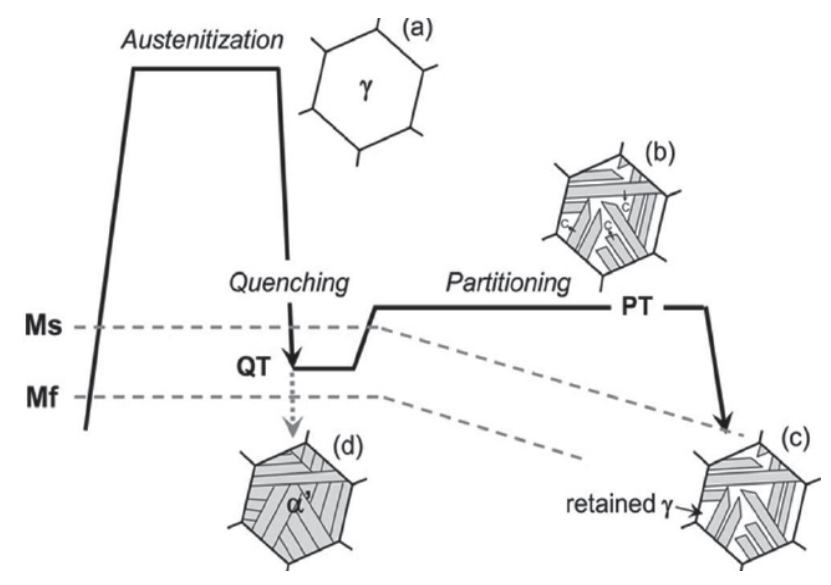

Figure 1 Schematic diagram of the Q\&P process [2]

Inversely, if the QT is too high, the content of retained austenite is too great for the sufficient enrichment with carbon to be obtained during the partitioning step. As a result, austenite remains unstable and it can transform into martensite during the final cooling to the room temperature [5]. As a consequence, the additional fraction of fresh untempered martensite will be present in the microstructure. For this reason, fresh martensite remains hard and brittle which impairs the mechanical properties of steel [5]. Moreover, if the partitioning time is too long and/or the temperature is too high, the unwanted carbide precipitates may form [2].

\section{EXPERIMENTAL}

The chemical composition of the $\mathrm{X} 46 \mathrm{Cr} 13$ martensitic stainless steel investigated in the present study is shown in Table 1.

Table 1 Chemical composition of $\mathrm{X} 46 \mathrm{Cr} 13$ steel

\begin{tabular}{|c|c|c|c|c|c|c|c|c|c|c|}
\hline Element & $\mathrm{C}$ & $\mathrm{Cr}$ & $\mathrm{Si}$ & $\mathrm{Mn}$ & $\mathrm{Ni}$ & $\mathrm{Mo}$ & $\mathrm{V}$ & $\mathrm{Al}$ & $\mathrm{Cu}$ & $\mathrm{Fe}$ \\
\hline Weight (wt \%) & 0.42 & 12.50 & 0.35 & 0.29 & 0.39 & 0.05 & 0.02 & 0.024 & 0.14 & $\mathrm{Bal}$. \\
\hline
\end{tabular}

In order to design the heat treatment parameters, the characteristic temperatures and the kinetics of phase transformations were determined through the dilatometric measurements with the use of Bähr $805 \mathrm{~L}$ dilatometer. The heat treatments were performed with the use of a dilatometric furnace. The registration of the changes in length as a function of time and temperature was performed using the DIL805L PRO program which is connected with the dilatometer. Various samples with the length of $9.7-10.2 \mathrm{~mm}$, in a form of cylindrical bars with a $3 \mathrm{~mm}$ diameter and the hollow tubes of $4 \mathrm{~mm}$ diameter and $1 \mathrm{~mm}$ thickness were used in the tests. Hardness in Vickers scale was measured with the use of the ZWICK/ROELL testing machine. The applied load was 19.6 N. The volume fraction of retained austenite after the Q\&P treatments was measured by the magnetic saturation method. In order to determine the volume fraction of retained austenite as well as the presence of carbon precipitates, the transmission electron microscopy (TEM) was used. TEM samples were grinded to $100 \mu \mathrm{m}$ of thickness and subjected to electrolytic etching up to the perforation. 
The heat treatment diagram is presented in Figure 1. Based on experimental results, the austenitizing of the samples at $1100{ }^{\circ} \mathrm{C}$ for 15 minutes was adopted. In the present study, different values of the quenching temperature (QT) as well as the temperature (PT) and time of partitioning (Pt) were tested. The values of QT varied between $25^{\circ} \mathrm{C}$ and $100^{\circ} \mathrm{C}$. The partitioning time was in the range of $5-15$ minutes and the partitioning temperature between $250^{\circ} \mathrm{C}-450^{\circ} \mathrm{C}$. Partitioning at the temperature below $250^{\circ} \mathrm{C}$ would result in a very long time of this process and hence, it would be ineffective. This is because the rate of diffusion of carbon atoms from supersaturated martensite to the areas of retained austenite is very slow at low temperatures. On the other hand, the use of a PT higher than $480^{\circ} \mathrm{C}$ can lead to the formation of carbide precipitates such as $\mathrm{M}_{23} \mathrm{C}_{6}$ and $\mathrm{M}_{7} \mathrm{C}_{3}$ in martensitic stainless steel [5].

In order to determine the theoretical austenite content as a function of QT, the Koistinen-Marburger's equation [6] was used:

$F_{\text {aust }}=e^{\left(\left(-1.1 \times 10^{-2}\right) \times(M S-Q T)\right)}$

where:

$F_{\text {aust }}$ - volume fraction of retained austenite

$M_{s}$ - martensite start temperature $\left({ }^{\circ} \mathrm{C}\right)$

$Q T$ - quenching temperature $\left({ }^{\circ} \mathrm{C}\right)$.

Based on the equation (1), five different quenching temperatures, which correspond to different contents of retained austenite that varied between of $20 \%-45 \%$ volume fractions, were determined. Selected temperatures are summarized in the Table 2.

Table 2 The values of quenching temperatures corresponding to given volume fraction of retained austenite, calculated from equation 1.

\begin{tabular}{|c|c|c|c|c|c|}
\hline Volume fraction of retained austenite from K-M equation & $20 \%$ & $23 \%$ & $28 \%$ & $35 \%$ & $45 \%$ \\
\hline Calculated value of the quenching temperature & $25{ }^{\circ} \mathrm{C}$ & $40{ }^{\circ} \mathrm{C}$ & $60{ }^{\circ} \mathrm{C}$ & $80{ }^{\circ} \mathrm{C}$ & $100{ }^{\circ} \mathrm{C}$ \\
\hline
\end{tabular}

\section{RESULTS}

\subsection{The influence of quenching temperature on hardness and microstructure of steel}

According to the Q\&P processing diagram (Figure 1), the samples were quenched at various quenching temperatures in the range of $25^{\circ} \mathrm{C}-100^{\circ} \mathrm{C}$. The hardness (the blue curve) and the volume fraction of retained austenite (the red curve) obtained after quenching at different temperatures are presented in Figure 2. Partitioning time and temperature were the same for all the samples, i.e. 5 minutes and $400{ }^{\circ} \mathrm{C}$ respectively. Two different areas can be seen in the diagram (Figure 2). In the Area I, the volume fraction of retained austenite increases and the hardness decreases as a function of QT. As seen in the graph, the initial drop in the hardness is due to the increase in the volume fraction of retained austenite. Above the critical point, where QT is c.a. $60^{\circ} \mathrm{C}$, an opposite relationship is observed (Area II). In this area, the volume fraction of retained austenite decreases rapidly and the hardness rapidly increases. The relation between the changes observed in Area I and Area II occurs because above the critical point the $M_{s}$ temperature of retained austenite is too high and therefore, retained austenite is not stable enough. For this reason, martensitic transformation takes place and it leads to the formation of fresh martensite [2, 5]. Due to the high hardness of fresh martensite, steel exhibits higher hardness in Area II for the same value of austenite volume fraction (about $34 \%$ ) with comparison to Area I. In Area I, for the $34 \%$ of retained austenite, the hardness of steel is equal to about 640 HV2 but in Area II, for the same volume fraction of retained austenite, the hardness is equal to about 665 HV2. However, additionally untempered martensite is also brittle and therefore, it significantly impairs the mechanical properties of the steel [5]. 


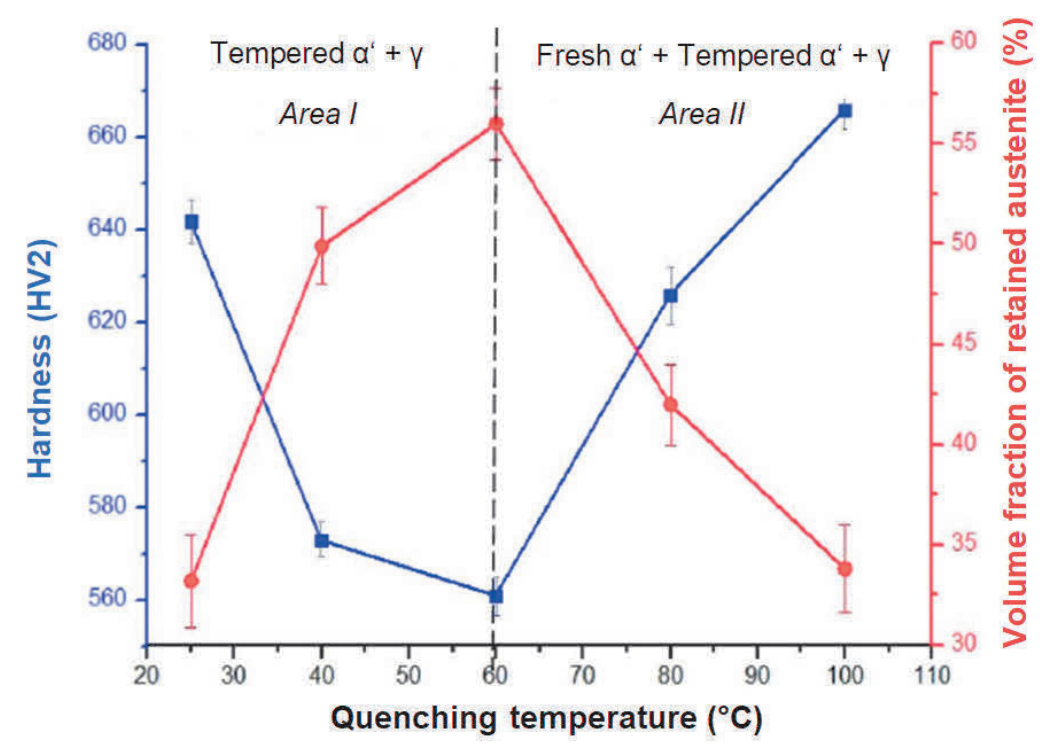

Figure 2 Hardness and the volume fraction of retained austenite as a function of quenching temperature for the specimens subjected to partitioning at $400{ }^{\circ} \mathrm{C}$ for 5 minutes

Martensitic transformation of unstable retained austenite during cooling after the partitioning step was shown in the dilatometric curves (Figure 3). For the samples, in which martensitic transformation did not occur, the curve was rectilinear up to the room temperature.

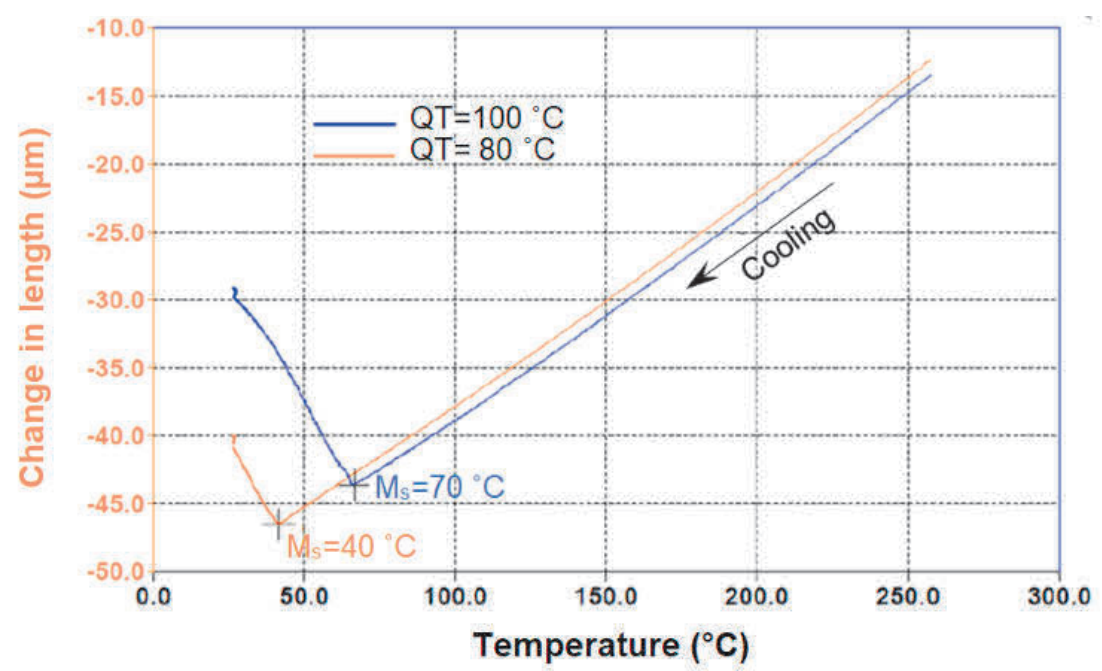

Figure 3 Dilatometric curves for samples after the Q\&P process: $\mathrm{PT}=400^{\circ} \mathrm{C}, \mathrm{Pt}=5 \mathrm{~min}$,

a) orange curve $\mathrm{QT}=80^{\circ} \mathrm{C}, \mathrm{b}$ ) blue curve $\mathrm{QT}=100^{\circ} \mathrm{C}$

\subsection{The influence of quenching temperature on hardness and microstructure of steel}

In order to investigate the effect of partitioning temperature on hardness of the samples different PT were selected: $250{ }^{\circ} \mathrm{C}, 300{ }^{\circ} \mathrm{C}, 350^{\circ} \mathrm{C}, 400{ }^{\circ} \mathrm{C}$ and $450^{\circ} \mathrm{C}$ for the time of 5 minutes. All samples were quenched at three different QTs: $25^{\circ} \mathrm{C}, 40^{\circ} \mathrm{C}$ and $60^{\circ} \mathrm{C}$. The results of the hardness measurements are presented in the diagram (Figure 4). It can be seen that for the same QT the increase in the partitioning temperature causes the decrease in hardness. The decrease results from the tempering process of martensite that occurs during the partitioning stage. As the tempering process is controlled by diffusion, the decrease in hardness is higher at higher PT. 


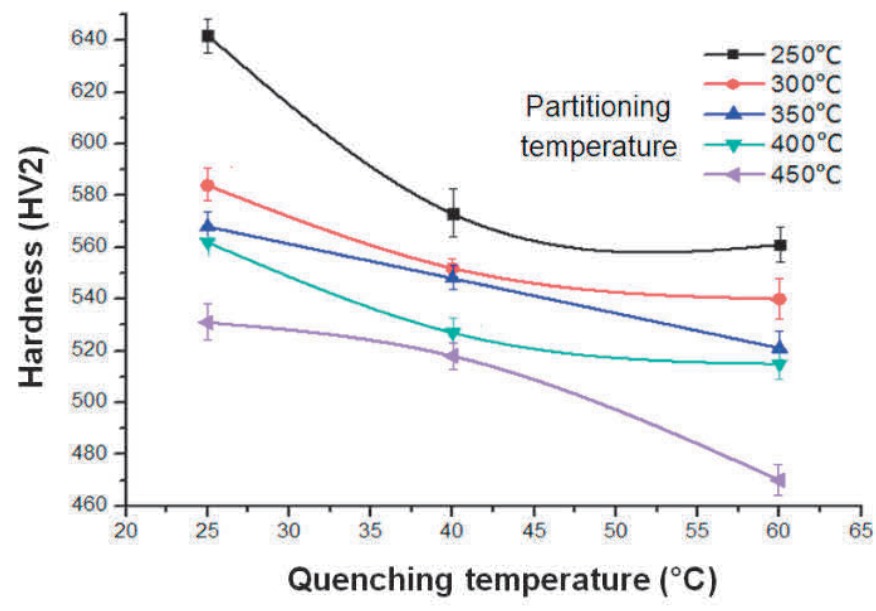

Figure 4 The relationship between hardness and quenching temperature for different partitioning temperatures; partitioning time for all the samples was 5 minutes

This diagram confirms the results discussed in the previous chapter that in the Area I, the hardness decreases with the increase in the quenching temperature, for the same partitioning temperature.

\subsection{The influence of Q\&P parameters on microstructure}

The Q\&P processes allowed for stable retained austenite to be obtained in the microstructure. This was observed during TEM investigations (Figure 5).
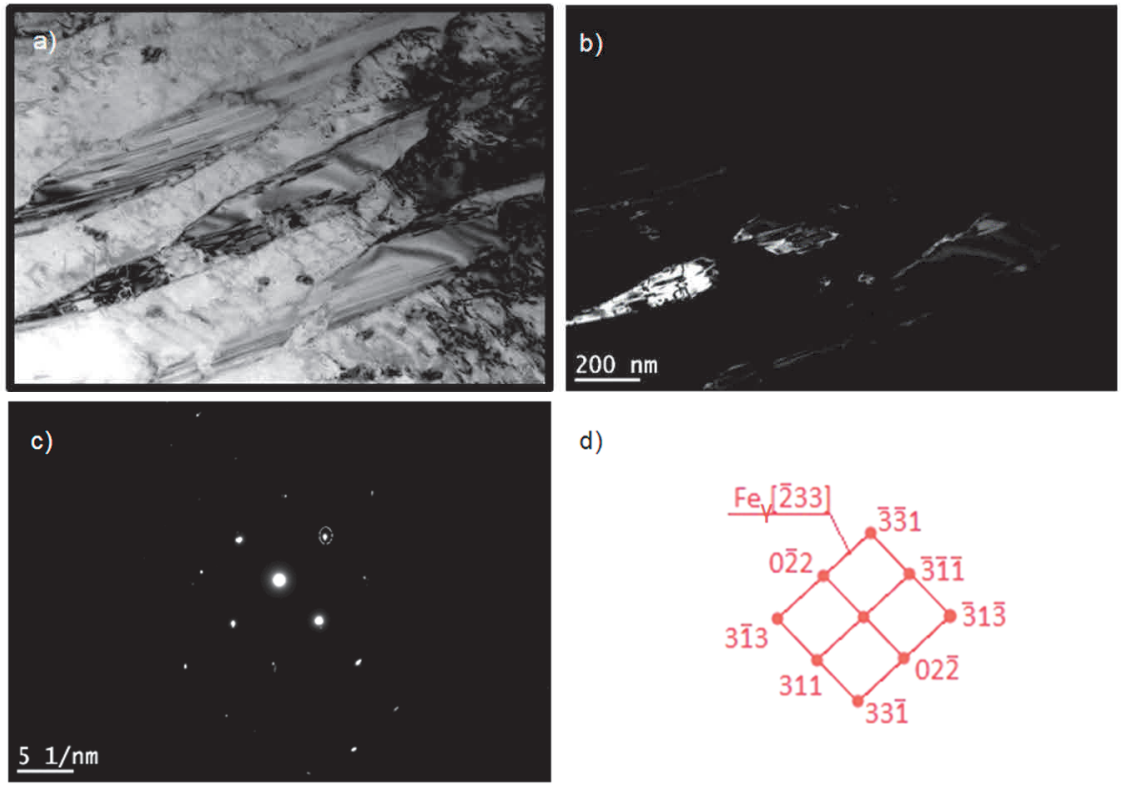

d)

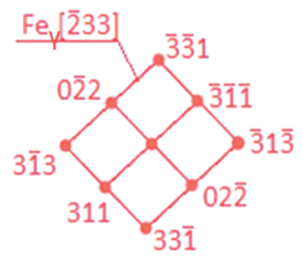

Figure 5 The microstructure of $X 46 \mathrm{Cr} 13$ steel after Q\&P processing: $\mathrm{T}_{\mathrm{A}}=1100{ }^{\circ} \mathrm{C}, \mathrm{QT}=40{ }^{\circ} \mathrm{C}$, $\mathrm{PT}=300^{\circ} \mathrm{C}, \mathrm{Pt}=5 \mathrm{~min}(\mathrm{a})$, (b) retained austenite with visible stacking faults.

The micrograph in (b) has been taken from a (331) reflex from retained austenite

Carbides precipitates occurred at the partitioning temperatures of $400{ }^{\circ} \mathrm{C}$ and $450{ }^{\circ} \mathrm{C}$ carbides precipitations occurred (Figure 6). At higher partitioning temperature, larger carbide precipitates were observed. Carbide precipitation precipitates are undesirable because they diminish the toughness of steel. This was also observed in other studies [5] that the partitioning carried out at too high temperatures led to the precipitation of carbides in steel. 

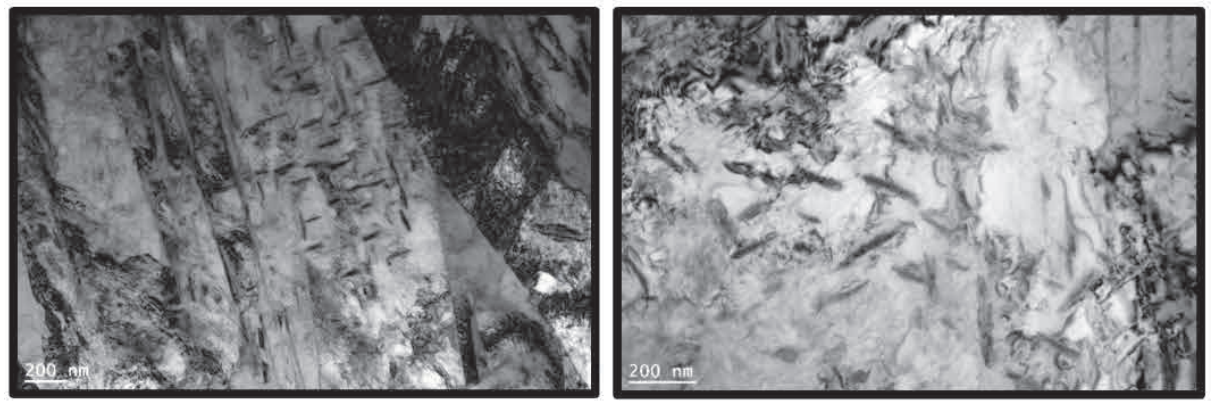

Figure 6 The Carbide precipitates ions observed in X46Cr13 steel after the Q\&P processing: TA $=1100{ }^{\circ} \mathrm{C}$,

$$
\mathrm{QT}=40^{\circ} \mathrm{C}, \mathrm{Pt}=5 \min (\mathrm{a}) \mathrm{PT}=400^{\circ} \mathrm{C}, \text { (b) } \mathrm{PT}=450{ }^{\circ} \mathrm{C}
$$

\section{CONCLUSION}

Martensitic stainless steel $\mathrm{X} 46 \mathrm{Cr} 13$ was subjected to the Q\&P processing at different quenching and partitioning temperatures. The main results of the study are as follows:

1) The content of retained austenite increases with the increased in the quenching temperature, whereas, the hardness decreases. However, after the critical point, the stability of austenite is not high enough and it transforms into martensite during cooling from the partitioning temperature. This leads to the formation of fresh martensite; to the drop in the austenite content and to the significant increase in hardness.

2) As the partitioning temperature increases, the hardness diminishes. This effect results from the martensite tempering process which is more intense during partitioning at the higher temperature.

3) Partitioning of steel at the temperature of $400^{\circ} \mathrm{C}$ or above that one leads to the precipitation of carbide. Its size depends on the partitioning temperature, i.e. greater precipitates were observed at higher partitioning temperatures.

\section{ACKNOWLEDGEMENTS}

This research work has been supported by Warsaw University of Technology and by thea Nanocarbain Research Project Nanocarbain (contract no. Lider/12/0040/l-9/17/ncbr/2018), financed by the National Centre for Research and development under the Lider IX program.

\section{REFERENCES}

[1] WANG, Li. and SPEER, J.G. Quenching and Partitioning Steel Heat Treatment. Metallography, Microstructure, and Analysis. 2013. vol. 2, no. 4, pp. 268-281.

[2] TSUCHIYAMA, T., TOBATA, J., TAO, T., NAKADA, N. and TAKAKIA, S. Quenching and partitioning treatment of a low-carbon martensitic stainless steel. Materials Science and Engineering A. 2012. vol. 532, no. 1, pp. 585-592.

[3] MOLA, J. and DE COOMAN, B.C. Quenching and partitioning processing of transformable ferritic stainless steel. Scripta Materialia. July 2011. vol. 65, no. 9, pp. 834-837.

[4] SKOŁEK, E., WASIAK, K. and ŚWIĄTNICKI, W.A., The microstructure and phase composition of 35 CrSiMn5-5-4 steel after quenching and partitioning heat treatment. Archives of Metallurgy and Materials. 2016. vol. 61, no. 3, pp. 1683-1688.

[5] MOLA, J. and DE COOMAN, B.C. Quenching and partitioning (Q\&P) processing of martensitic stainless steels. Metalurgical and Materials Transaction A. 2013. vol. 44, no. 2, pp. 946-967.

[6] SPEER, J.G., MATLOCK, D., DE COOMAN, B.C. and SCHROTH, J.G. On the Definitions of paraequilibrium and orthoequilibrium. Scripta Materialia. 2005. vol. 52, no. 1, pp. 83-85. 